\title{
Optimization of the cooling circuit and thermo-mechanical analysis for the extraction grid of ELISE
}

\author{
R. Nocentini, R. Gutser, B. Heinemann, M. Fröschle, R. Riedl \\ Max-Planck-Institut für Plasmaphysik, Postfach 1533, D-85740 Garching, Germany
}

\begin{abstract}
The NNBI test facility ELISE ("Extraction from a Large Ion Source Experiment"), presently under construction at IPP, will have an extraction area with the same width and half the height of the ITER source, acceleration up to $60 \mathrm{kV}$, for $10 \mathrm{~s}$, every $180 \mathrm{~s}$, and plasma generation up to $1 \mathrm{~h}$. Electrons are co-extracted from the ion source. Suppression magnets in the extraction grid deflect the electrons onto the extraction grid surface. For $30 \mathrm{~mA} / \mathrm{cm}^{2}$ extracted electron current density and $10 \mathrm{kV}$ extraction voltage, localized power density is in the order of $39 \mathrm{MW} / \mathrm{m}^{2}$ near the grid apertures and a total heat load of $150 \mathrm{~kW}$ is deposited onto each extraction grid segment. Heat removal is provided by a water circuit inside the grid. For ELISE, a new cooling circuit has been developed to provide a more reliable operation. The optimization of the cooling circuit and the thermo-mechanical analysis of the extraction grid of ELISE, considering maximum grid temperature, mechanical stresses and grid deformation, has been performed using the codes KOBRA3, TrajAn, the ANSYS finite element package and the fluid dynamics code CFX.
\end{abstract}

Keywords: Neutral Beam Injection, ITER, negative ion source, RF source, finite elements, extraction grid

\section{Introduction}

RF negative ion sources have been successfully developed at IPP in recent years [1,2,3]. ITER [4,5] relevant parameters of accelerated current density (30 $\mathrm{mA} / \mathrm{cm}^{2}$ with $\mathrm{H}^{-}$and $20 \mathrm{~mA} / \mathrm{cm}^{2}$ with $\left.\mathrm{D}^{-}\right)$and extracted electron to ion current ratio lower than 1 have been achieved with a prototype source at IPP. As a consequence the RF source has been chosen for the ITER NBI $[6,7]$.

The test facility ELISE ("Extraction from a Large Ion Source Experiment") is now under construction at IPP and, with approximately 4 times the size of the prototype source, it represents an intermediate step in the development of the ITER source [8].

The characteristics of ELISE are: plasma production for $1 \mathrm{~h}$, acceleration of a negative ion beam up to $60 \mathrm{keV}$ for 10 seconds, every 180 seconds, via a $1000 \mathrm{~cm}^{2}$ ITER-like extraction area. During the last years two concepts for the extraction and acceleration system have been proposed and tested for the $1 \mathrm{MV}$ accelerator of the ITER NBI: the MAMUG and the SINGAP configurations $[9,10]$. SINGAP is the reference design for the extraction system of ELISE that is equipped with three grids: Plasma Grid (PG), Extraction Grid (EG) and Grounded Grid (GG) [11]. The ø $14 \mathrm{~mm}$ extraction apertures are arranged in 4 beam groups $(5 \times 16$ apertures, spacing $20 \mathrm{~mm} \times 20 \mathrm{~mm}$ ). Negative ions are extracted from the source with up to $10 \mathrm{kV}$ voltage set in the $6 \mathrm{~mm}$ gap between EG and PG.

Due to the same polarity, electrons are extracted too. The EG is designed to suppress the co-extracted electrons via a periodic arrangement of $\mathrm{Sm}_{2} \mathrm{Co}_{17}$ magnet rods (section $6 \times 5 \mathrm{~mm}^{2}$, remanence on surface $1.10 \mathrm{~T}$ ), with alternating magnetization, which are embedded in the EG in between the aperture rows to generate the electron deflection field (EDF). In addition a magnetic filter field (FF) is generated in front of the PG by an intense electric current of several $\mathrm{kA}$ flowing through the plasma grid in vertical direction [12] to filter electrons in the ion source to energies lower than $2 \mathrm{eV}$ and for sufficient suppression of co-extracted electrons [2]. Electrons are deflected onto the EG in crescent-shaped profiles as described in section 2, while ions trajectories are not significantly affected. A water cooling is necessary to remove the heat from the EG.

Thermal gradients in the EG cause deformations, in particular bowing. This changes the distance between PG and EG and affects the ion beam optics. In addition thermo-mechanical stress cycles cause material fatigue. During source conditioning, electron to ion current ratio can be considerably higher than 1 [3]. Past experiments at IPP have shown a local melting of the EG surface [13]. Furthermore a higher extraction voltage results in higher negative ion current [14]. For these reasons a significant effort has been undertaken at IPP to develop an optimized cooling system for the EG.

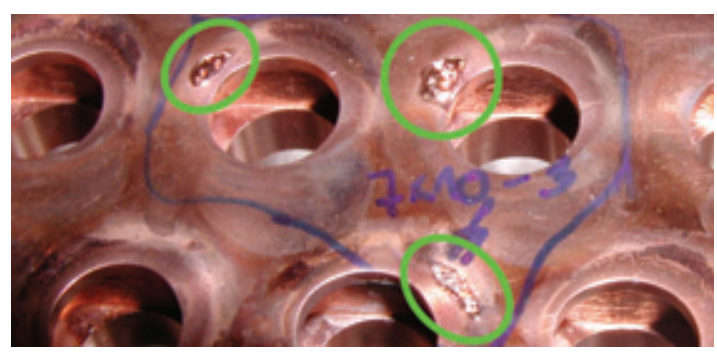

Figure 1 Extraction grid of BATMAN experiment damaged by co-extracted electrons

This study refers to an extracted electron current density of $30 \mathrm{~mA} / \mathrm{cm}^{2}$ and extraction voltage of $10 \mathrm{kV}$, resulting in a power load of $150 \mathrm{~kW}$ on each EG 
segment (containing four beam groups of 320 apertures, see figure 5). These values, close to those required for the ITER source [2], have been chosen so that the water temperature in cooling channels remains below the boiling point and therefore a relatively simple one-phase model can be used for the computational fluid dynamics (CFD) simulations. However the cooling circuit of the ELISE EG allows higher heat load regimes, as shown later in section 4.

\section{Electron trajectories and power loads}

In SINGAP EDF and FF are in "parallel" configuration, as shown in figure 2 , producing two power density profiles with different intensities for added and subtracted fields, as shown in Figure 3. Most of the negative ion sources for NBI worldwide use "orthogonal" EDF with respect to the FF, also shown in figure 2. This produces a rotation by $90^{\circ}$ of the power load distribution on the EG surface, shown in Figure 3 and a power density profile with same intensity for each magnetization direction. The ELISE EG has been designed to allow both configurations, giving the possibility of a comparison of the respective performances in the same ion source.

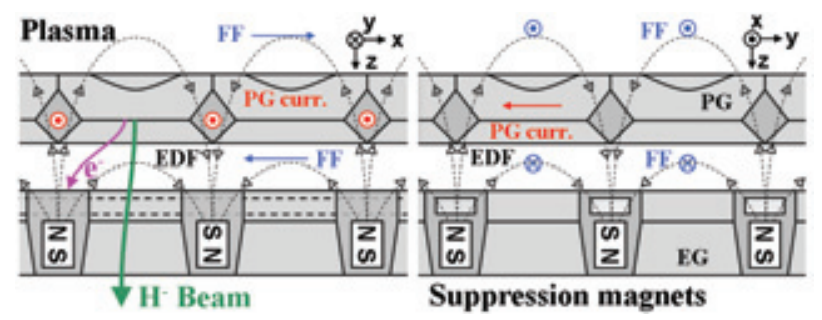

figure 2 parallel (left) and orthogonal (right) configurations of $\mathrm{EDF}$ with respect to FF with ion and electron trajectories schematically represented.
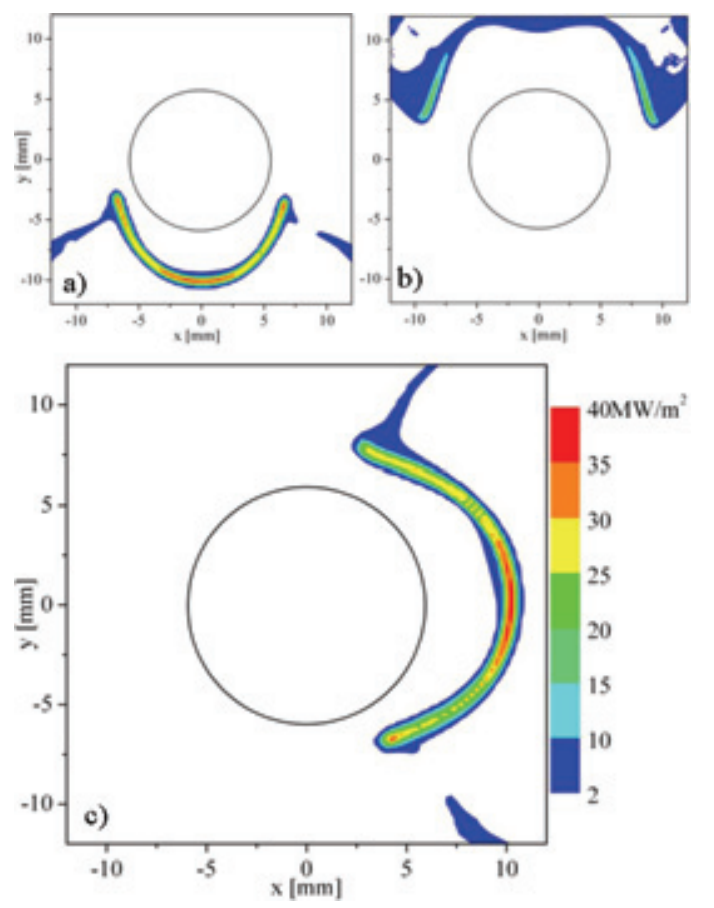

Figure 3 Power density deposition by co-extracted electrons (for $10 \mathrm{kV}$ acceleration and $30 \mathrm{~mA} / \mathrm{cm}^{2}$ current density) for EDF parallel to FF in subtracted (a) and added (b) fields, and for EDF orthogonal to FF (c).
The electron power distribution on the EG surface has been evaluated for the orthogonal and parallel configurations using the FEM code ANSYS [15] for the 3D magnetic field analysis, the KOBRA3 [16] code for the ion trajectories in combination with the TrajAn code $[17,18]$ for the electron trajectories.

\section{Optimization of cooling channels}

\subsection{Number and geometry of the cooling channels}

The SINGAP cooling system consists of straight cooling channels of $5 \times 2 \mathrm{~mm}$ section, one channel between each row of apertures. The relatively wide water channel acts as a resistance to the flow of heat. A cooling channel geometry based on multiple channels with high aspect ratio, and larger cooling surface, has been investigated. This design is based on the IPP experience with the calorimeter panels of the ASDEX Upgrade for the positive NBI system [19] and on an analysis of the geometry of the cooling channels of rockets combustion chambers [20]. For better cooling efficiency it is not possible to simply increase the water velocity inside the cooling channels above the design value of $12 \mathrm{~m} / \mathrm{s}$ as this may trigger cavitation and material erosion.

A simplified 2D conceptual study has been performed in ANSYS by means of a thermal model. Four different channel geometries, as defined in Figure 4 , have been compared. In this preliminary evaluation a constant heat transfer coefficient of $80000 \mathrm{~W} / \mathrm{m}^{2} \mathrm{~K}$ and water temperature of $55^{\circ} \mathrm{C}$ have been used. It is evident how a higher number of channels, and a larger aspect ratio, can improve the cooling efficiency considerably. A solution with multiple channels has been chosen also for the cooling circuit of the EG in the SPIDER testbed [21].

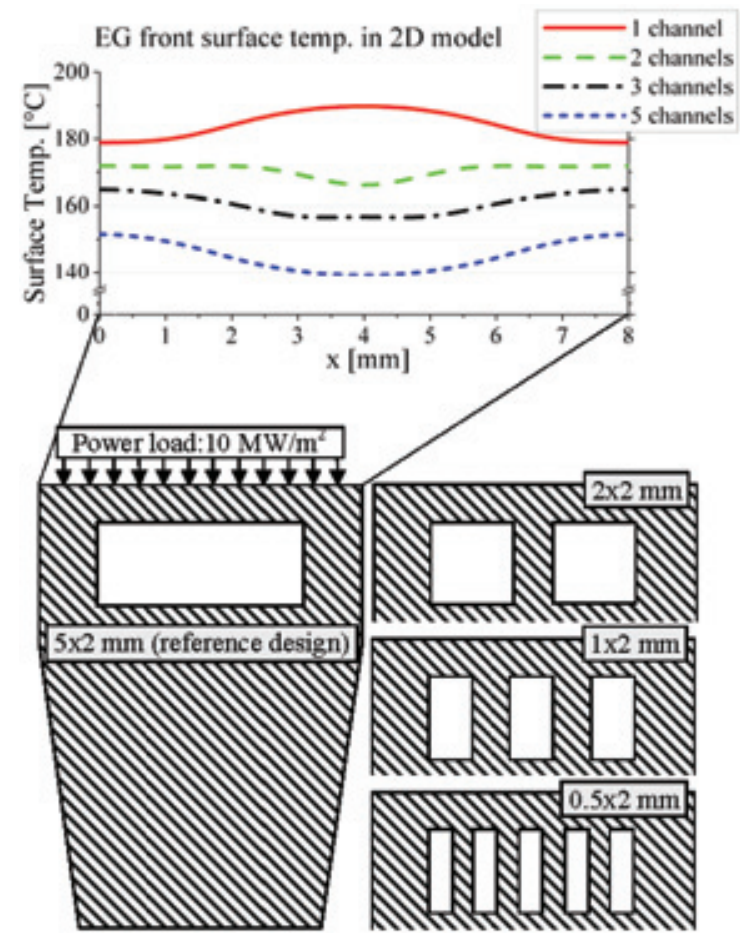

Figure 4 Temperature distributions on the front surface of the EG model for the four different cooling channel geometries 
that have been compared in a $2 \mathrm{D}$ conceptual study with a uniform power load.

\subsection{Cooling circuit for ELISE EG}

Curved cooling channels give the possibility to optimize the cooling of the EG for both orientation of EDF (parallel and orthogonal) and to adapt better to the crescent-like power load distribution of co-extracted electrons. Curved channels are reasonably machinable down to $1 \mathrm{~mm}$ width for $2 \mathrm{~mm}$ depth, therefore the solution with 3 channels has been chosen. This geometry has been adapted to the ELISE EG aperture geometry, using two curved channels and one straight channel in the middle, as visible in Figure 5. The curved channels have enlarged section between the beam groups to obtain similar pressure drop and water flow as the straight channels. This optimized channel design has higher pressure drop compared to the SINGAP design. To limit the increase in pressure losses, the cooling circuit has been split into two, with one inlet and one outlet for each side of the grid segment. The water flow for the SINGAP configuration is $2 \mathrm{~kg} / \mathrm{s}$ for each grid segment, leading to $12 \mathrm{~m} / \mathrm{s}$ water velocity in the cooling channels. The same water velocity has been kept for ELISE, giving $2.4 \mathrm{~kg} / \mathrm{s}$ for each EG segment.

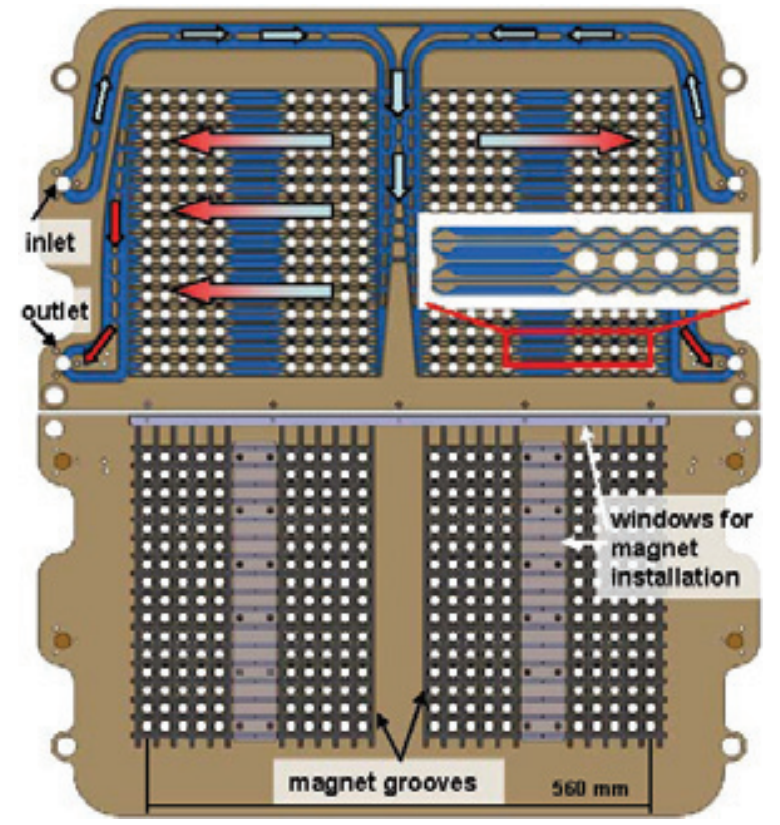

Figure 5 ELISE EG. Upper segment: cooling circuit. Bottom segment: magnet grooves in the back side of the EG, for both EDF configuration.

\section{Results of CFD and FEM models}

A series of $3 \mathrm{D}$ simulations has been performed to compare the ELISE EG cooling circuit design to the SINGAP reference design.

Due to the localized heat load a very fine surface mesh, with a typical size of $0.25 \mathrm{~mm}$ is required to model thermal gradients accurately, as shown in Figure 6. To limit the number of elements, only a portion of the grid has been modelled. Boundary conditions permit to take advantage of symmetry and periodicity.
Considering the relatively complex geometry of the cooling circuit, fluid-thermal calculations have been performed by means of the CFD code CFX [22], to evaluate local non-uniformities of the heat transfer coefficient, as shown in Figure 7, and to provide an accurate calculation of the EG temperature field, as shown in Figure 8.

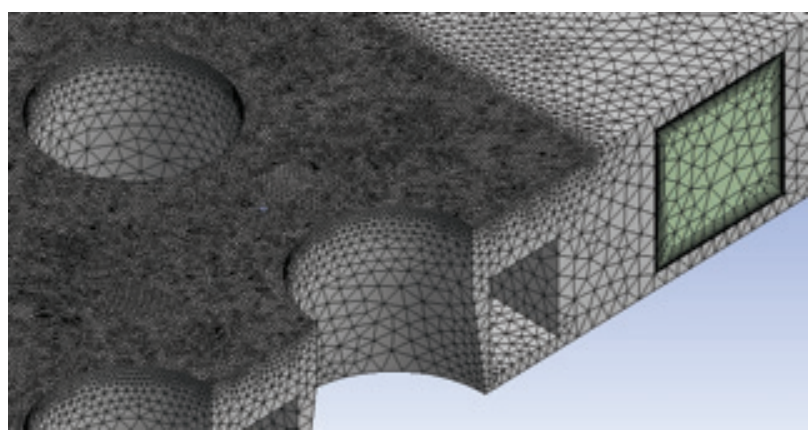

Figure 6 EG Model meshed in ANSYS CFX.

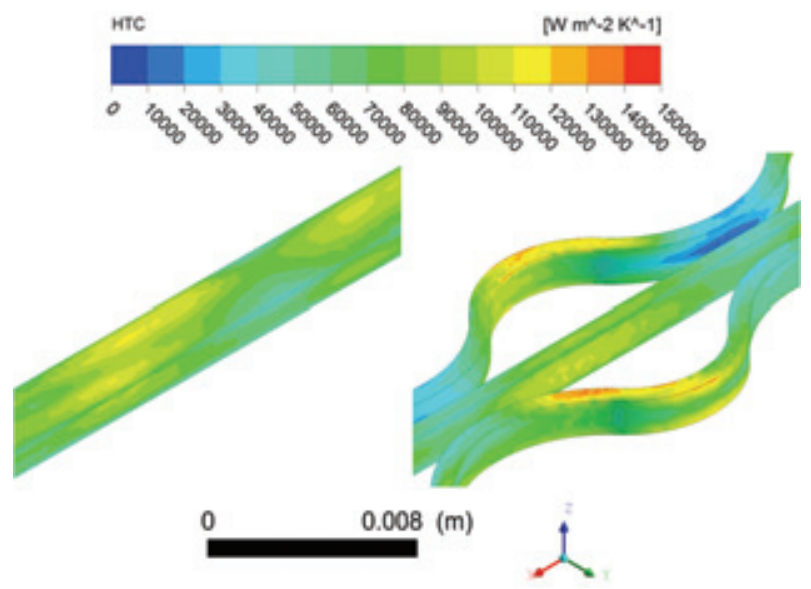

Figure 7 Heat transfer coefficient distribution in EG cooling channels for SINGAP (left) and ELISE (right), EDF and FF in orthogonal configuration.

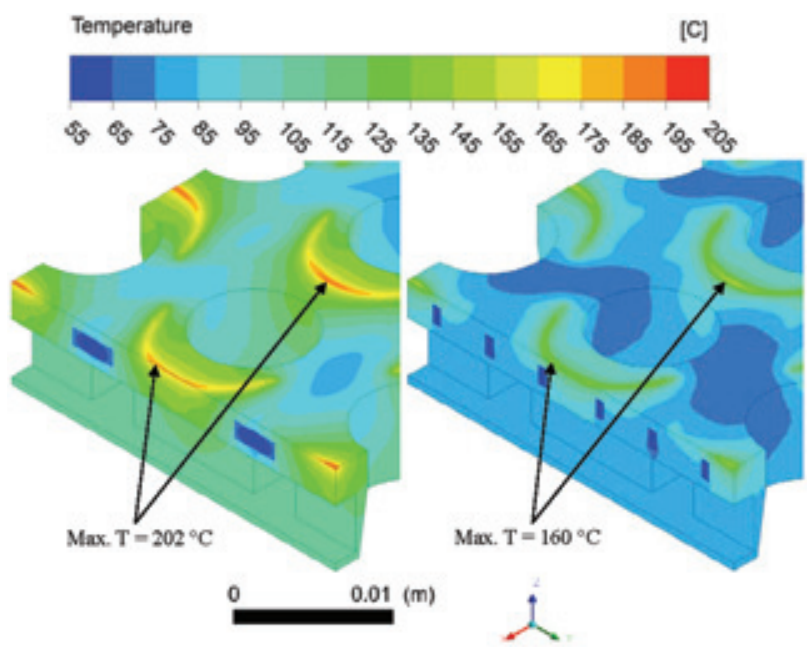

Figure 8 Temperature distribution in SINGAP (left) and ELISE (right) for EDF and FF in orthogonal configuration.

To model the flow near the wall in the CFD simulations the shear stress transport (SST) model has been used. All the models have channels meshed with 30 inflation layers to achieve an accurate resolution of the boundary layer. Mesh independence studies have been 
performed. For the thermo-mechanical calculations the temperature field from $\mathrm{CFX}$ has been imported in ANSYS, where a linear-elastic model has been implemented.

The results of the simulations in Table 1 show significant improvements of the ELISE design compared to the SINGAP design.

Table 1 Summary of results of CFD and FEM calculations for SINGAP and ELISE EG: max. surface temperature, max. water temperature, bowing deformation, max. mechanical stresses. For absolute temperatures add $55{ }^{\circ} \mathrm{C}$ inlet water temperature.

\begin{tabular}{lllll}
\hline & EDF-FF & SINGAP & ELISE & $\begin{array}{l}\text { Diff. } \\
{[\%]}\end{array}$ \\
\hline Max. $\Delta \mathrm{T}$ & paral & 123 & 106 & -16 \\
surf. $\left[{ }^{\circ} \mathrm{C}\right]$ & ortho & 147 & 105 & -29 \\
Max. $\Delta \mathrm{T}$ & paral & 88 & 77 & -13 \\
water $\left[{ }^{\circ} \mathrm{C}\right]$ & ortho & 74 & 64 & -14 \\
Max. $\Delta \mathrm{z}$ & paral & 1.11 & 1.07 & -4 \\
{$[\mathrm{~mm}]$} & ortho & 1.10 & 0.40 & -71 \\
$\mathrm{Max} . \sigma$ & paral & 194 & 161 & -17 \\
{$[\mathrm{MPa}]$} & ortho & 252 & 125 & -50 \\
\hline
\end{tabular}

The channel design for ELISE provides in addition a cooling performance that is less dependent on the distribution of the power deposited onto the EG surface, therefore representing a more flexible solution.

Inlet water temperature is $55^{\circ} \mathrm{C}$. The calculated maximum water temperature remains below $150^{\circ} \mathrm{C}$ therefore no boiling is present in the cooling channels as pressure at the EG outlet is set to 6 bar.

The critical heat flux for the EG cooling channels estimated according to Gunter [23] is $18.7 \mathrm{MW} / \mathrm{m}^{2}$. The calculated maximum heat flux on the channel surface is $7 \mathrm{MW} / \mathrm{m}^{2}$ for SINGAP and $5.5 \mathrm{MW} / \mathrm{m}^{2}$ for ELISE, therefore assuring an increased margin of safety. This is a significant advantage also for $\mathrm{D}^{-}$operation, where the co-extracted electron to ion current ratio is higher, and higher extraction voltage is required [2].

A pressure drop of 5 bar is calculated for the ELISE EG cooling circuit. This is considered an acceptable increase with respect to the 3.6 bar calculated for SINGAP.

In this study, pressure loads and the corresponding mechanical stresses are not taken into account, since they are not relevant for the small cooling channels. However they are important for the manifolds as has been shown in a specific separate analysis.

\section{Conclusions}

For the design of the EG for the ELISE test bed, the cooling circuit has been improved to reduce maximum surface temperature and thermo-mechanical stresses in one of the most critical components for the negative ion source.

Electron trajectories and the resulting power density profiles on the EG surface have been determined for parallel and orthogonal configurations of the electron deflection field with respect to the filter field.

An optimized water circuit based on small channels with high aspect ratio has been developed and adapted to the complex geometry of the EG to provide a more efficient and uniform cooling of the grid.

From several CFD and FEM calculations, it has been shown that the new ELISE design provides considerable advantages compared to the SINGAP reference design. Maximum grid surface temperatures, maximum water temperatures, bowing and mechanical stresses in the grid are reduced and operational range is increased at the cost of a modest increase in pressure drop.

Higher heat load regimes, with possibility of subcooled nucleate boiling in the cooling channels, should be investigated in the future.

\section{Acknowledgments}

The work reported here is part of the construction of the ELISE test facility which is being supported by a contract from Fusion for Energy (F4E-2009-0PE-32-01) (with an amount of 4 Mio. Euro). The opinions expressed herein are those of the authors only and do not represent the Fusion for Energy's official position.

\section{References}

[1] E. Speth et al., Nucl. Fusion 46, 220 (2006).

[2] P. Franzen et al., Nucl. Fusion 47, 264 (2007).

[3] A. Stäbler et al., Fusion Eng. Des. 84, 265-268 (2009).

[4] ITER Technical Basis, Design Description Document, Section 5.3 (DDD 5.3), International Atomic Energy Agency, (2001).

[5] ITER Technical Basis, ITER EDA Documentation Series No. 24 (Plant Description Document, Section 2.5.1), International Atomic Energy Agency, (2002).

[6] R. Hemsworth et al., Rev. Sci. Instrum. 79, 02C109 (2008).

[7] R. Hemsworth et al, Nucl. Fusion 49, 045006 (15pp) (2009).

[8] B. Heinemann et al., "The negative ion source test facility ELISE", this conference

[9] H. de Esch et al., Fusion Eng. Des. 84, 669-675 (2009).

[10] M. Taniguchi et al., Rev. Sci. Instrum. 79, 02C110 (2008).

[11] B. Heinemann et al, Fusion Eng. Des. 84, 915-922 (2009).

[12] R. Nocentini et al., Fusion Eng. Des. 84, 2131-2135 (2009).

[13] R. Gutser, Technical Report IPP 4/286 (2006).

[14] U. Fantz et al., Nucl. Fusion 49, 125007 (2009).

[15] ANSYS, release 12.1, ANSYS Inc. (2009).

[16] P. Spädtke et al., GSI Report 89-09, (1989).

[17] R. Gutser et al., Plasma Phys. Control. Fusion 51 (2009) 045005 (14pp).

[18] R. Gutser at al., AIP Conf. Proc. 1097, pp. 297-306 (2009).

[19] R. Kreutz et al., DATF/KTG Jahrestagung Kerntechnik, Tagungsbericht, S.769-776 (1985)

[20] M. Wadel, NASA TM-206313, (1998).

[21] D. Marcuzzi, et al., Fusion Eng. Des., in press, (2010).

[22] ANSYS CFX, release 12.1, ANSYS Inc. (2009). 
[23] F.C. Gunther, Trans. Am. Soc. Mech. Eng. 73, 115-123 (1951). 